\title{
Determinants of Intercountry Internet Diffusion Rates
}

\author{
By Phanindra V. Wunnava and Daniel B. Leiter*
}

\begin{abstract}
This article employs cross-sectional data from 100 countries to analyze the main determinants of intercountry Internet diffusion rates. We set up an empirical model based on strong theoretical foundations, in which we regress Internet usage on variables that capture social, economic, and political differences between these countries. Our results support past findings that economic strength, infrastructure, and knowledge of the English language positively affect Internet connectivity. In addition to these indicators, the openness of a country, tertiary enrollment, and income equality are found to also have a significant positive effect on Internet diffusion.
\end{abstract}

\section{I}

\section{Introduction}

EVER SINCE THE RELEASE of the first graphical web browser in 1993, the Internet has experienced exponential growth. Today, nearly 16 years later, the Internet has become an incredibly valuable informational resource, housing over 11 billion websites. Since 2000, the number of users has tripled, with current estimates of worldwide Internet users being over 1 billion. However, diffusion rates across countries vary tremendously; in fact, many developing countries have penetration rates that are less than $1 / 100^{\text {th }}$ of those found in wealthy

*Phanindra V. Wunnava (the corresponding author) is David K. Smith Professor of Applied Economics at Middlebury College, Middlebury, VT 05753, and a Research Fellow at IZA in Bonn, Germany; e-mail: wunnava@middlebury.edu; http://www.middlebury. edu/ wunnava. Daniel B. Leiter is a fixed income analyst at Morgan Stanley, New York City; e-mail: Daniel.Leiter@morganstanley.com. We would like to thank an anonymous referee and the editor of this journal for their constructive comments. We also would like to thank William Warren for his excellent editorial suggestions, and Brenda Ellis for her timely research assistance. An earlier version of this article was circulated as an IZA (Institute for the Study of Labor) discussion paper (\#3666). The usual caveats apply.

American Journal of Economics and Sociology, Vol. 68, No. 2 (April, 2009).

(C) 2009 American Journal of Economics and Sociology, Inc. 
European countries. To date, Europe and North America, which represent a mere 17.5 percent of the total world population, house close to 50 percent of worldwide Internet users. ${ }^{1}$ To make matters worse, the "digital divide" is steadily increasing, according to the International Telecommunications Union. Given that the Internet has revolutionized communication and information, and even impacts the cultural, economic, and political development of a country, it is important to try to understand what the primary factors are that account for this divide.

II

\section{Previous Literature}

THE UNEVEN ADOPTION OF TECHNOLOGY among countries is not an Internet-specific phenomenon. Economists have long pointed out that rich countries are usually technologically more advanced than their poor counterparts. However, the difference of diffusion rates in the case of the Internet is quite extreme. Since it is very unlikely that income alone can explain this divide, various studies, the most important of which are described below, have been conducted in order to discover the most important determinants of intercountry Internet diffusion rates. Further studies are discussed as part of the theoretical framework in Section III.

Hargittai (1999) is one of the first economists to have studied the spread of the Internet across nations. Her research aims to find the primary reasons for the international variation in Internet connectivity within the member states of the Organization for Economic Cooperation and Development (OECD). Hargittai argues that there may be a number of factors that influence Internet diffusion, including economic indicators, human capital, the legal environment, and existing technologies within a country. Her findings show that even among OECD countries, which have similar levels of social and economic development, economic strength does matter when it comes to predicting diffusion rates.

Beilock and Dimitrova (2003) extend the focus of research on diffusion rates to 105 countries. Unlike most previous studies, they include countries that have vastly different socioeconomic levels of 
development. Their results confirm that GNP per capita is, by far, the most important determinant of Internet usage rates, but that the effect tapers off as GNP per capita increases. They also show that the political and economic openness of a country, as well as existing infrastructure such as telephone lines, have a positive impact on Internet usage.

Guillen and Suarez (2001) use cross-sectional data from 141 countries to test whether favorable conditions for entrepreneurship and investment as well as competition and privatization of the telecommunications industry accelerate the adoption of the Internet. Their findings support the claim that income, infrastructure, and proficiency in English matter more than public policy. Guillen and Suarez (2004) extend previous research by showing that regulatory, political, and sociological variables are also responsible for some of the difference in penetration rates across countries.

Crenshaw and Robison (2006) analyze the main factors contributing to the change in the number of Internet hosts for approximately 80 countries from 1995 to 2000. They employ numerous measures of globalization to determine whether a country's openness has a positive impact on Internet growth. Among their most interesting findings is that countries with a larger urban population and stronger participation within a global network of urban civilization will develop the Internet faster than others. Their work also suggests that a government's enforcement of property rights seems to have a significant positive effect on Internet growth. They conclude that countries that remain "isolates" in the global system are at a large disadvantage compared to their counterparts in terms of Internet diffusion.

III

\section{Theoretical Framework}

IN THIS SECTION OF OUR ARTICLE, we lay out the theoretical framework on which our analysis relies. The hypotheses we construct are based on economic theory and on findings presented in previous literature. They reflect our expectations of how Internet usage ought to be affected in a given scenario. For each of the following propositions we 
include at least one corresponding independent variable in our empirical model, which we present in Section IV.

Hypothesis 1. Countries with a higher GDP per capita are more likely to have higher penetration rates.

As already mentioned above, this is a hypothesis that holds in general when it comes to adopting new technologies. Richer countries have well-developed market economies and well-established legal systems, and as a result are able and willing to invest more in research and development and innovation. Given that innovation relating to the Internet is taking place at an unprecedented pace, this should play a very important role. All serious econometric studies that have been conducted on diffusion rates agree that GDP per capita is indeed a very significant determinant of Internet diffusion.

Hypothesis 2. Countries with more developed telecommunication and technology infrastructures are more likely to have higher penetration rates.

The Internet is a fairly advanced technology in that it requires a well-functioning telecommunications network to be present in order to operate. At the beginning of the Internet era, the presence of a traditional telephone line per computer was necessary in order to be able to connect to the net via modem. However, over the last five years, information transmission technology has advanced dramatically. Innovation has paved the way for a much faster Internet, so-called broadband, which, depending on the technology, requires only a single phone line for an entire network of computers (all types of DSL), or even none at all (cable, satellite, fiber optics). While such technologies are readily available in most developed countries, their availability is extremely limited in less developed parts of the world.

Of course, telecommunication networks alone are not sufficient for Internet connectivity; computers are needed as well. Our data show that the number of personal computers per country varies considerably more than the number of telephone mainlines, although the two are closely correlated.

While Arnum and Conti's (1998) study stands out for having employed numerous measures for infrastructure, most econometric studies on Internet diffusion have at least included the number of telephone lines per 1,000 inhabitants as an infrastructure variable, 
which they have found to be significant. However, as pointed out above, we would expect the significance of traditional telephone infrastructure to decrease over time as the availability of broadband and wireless technologies increases. In this sense, computer and technology infrastructure may be a better predictor of Internet usage.

Hypothesis 3. Countries with higher educational standards and literacy rates are more likely to have higher penetration rates.

There are many reasons why this hypothesis should hold, the most obvious being that the World Wide Web and e-mail are currently entirely text-based, implying that literacy is required in order to be able to actually use the Internet. Although there are some ongoing efforts to "vocalize" the Internet, such as Opera's text-to-speech engine, ${ }^{2}$ it will be a long time before such programs, along with dictating software, will truly lessen the need for literacy.

Another, perhaps less apparent, reason supporting this hypothesis is that academic institutions play an essential role in adopting new technology. Indeed, schools were among the first institutions to heavily make use of the Internet, and in doing so introduced young people to this new form of media. Today, research and other important aspects of education rely on the use of the Internet; hence, one can argue that education also promotes the adoption of the Internet in this sense.

There are a couple of studies (Chinn and Fairlie 2004; Guillen and Suarez 2004) that attempt to analyze the effect of literacy and education on penetration rates; however, literacy does not end up being a significant variable in either. We believe that there are essentially two problems with using literacy as a variable. First, the data are quite limited. In fact, in Guillen and Suarez's study, the data set decreased by a third when employing this variable. Second, literacy may not truly be enough to ensure that a person is actually able to use a computer. It may be that some other measures such as years of schooling or enrollment statistics deliver a more complete picture. To circumvent these issues, this study employs gross tertiary enrollment as a measure of education.

Hypothesis 4. Countries with a large percentage of their population living in urban areas are more likely to have higher penetration rates. 
In general, cities are better networked than rural areas. This is mostly thanks to practical and economic reasons. It is not only harder to build a communications network that spreads over vast territories, but it is also less interesting for firms from a profit-maximizing perspective, since firms want to target as many consumers as possible at the lowest cost possible. Therefore, it is plausible to assume that countries in which people tend to live in cities benefit from higher penetration rates. Studies such as Kay and Xiaoming (2004) and Crenshaw and Robison (2006) have found urban population to have a significant impact on Internet diffusion.

Hypothesis 5. Countries in which the population has a high level of English proficiency are more likely to have higher penetration rates.

Literacy and education may not be enough to guarantee an "enjoyable" Internet experience. English is currently by far the most commonly used language on the Internet, with estimates of over 50 percent of all websites being written in English. These numbers are so high because many nonnative English speakers choose to publish their websites in English in order to attract more surfers to their site. While the number of native Chinese users has increased more than threefold over the last five years, Chinese is rarely used as a lingua franca, and English will likely continue to be the main second language used for nonnative speakers. Most researchers have included some measure of English proficiency in their models and have found it to have a significant positive impact on Internet usage.

Hypothesis 6. Countries with less income inequality are more likely to have higher penetration rates.

It has been argued that higher income inequality within a country may have a negative effect on Internet diffusion because fewer people will be able to afford to pay subscription and connection fees. Unfortunately, Hargittai (1999) is among the very few researchers to test this hypothesis. Her results show that, among the OECD countries, income inequality does not have a significant effect on Internet connectivity.

Hypothesis 7. Countries that are politically less free are more likely to have lower penetration rates.

A politically unfree and unstable country is likely to hinder the usage of new media in general. This is particularly true when it comes 
to the Internet, where anti-government websites are only a click away, and typically hard to censor. Thus, it is reasonable to assume that countries that are less free will have lower penetration rates, partly due to the problems that the Internet creates for their governments. In fact, Buchner (1988) demonstrates that Communist countries tend to have fewer telephone lines per capita than their counterparts, and that this difference is indeed primarily due to the regime itself. It would therefore not be surprising to see this phenomenon also apply to the Internet.

\section{IV}

\section{Methodology and Empirical Analysis}

OUR METHODOLOGY EMPLOYs weighted least squares estimation ${ }^{3}$ in order to test all of the above hypotheses. The dependent variable in our model is the Internet penetration rate, which is measured per 1,000 inhabitants:

$$
\begin{aligned}
\text { INTERNET }_{i}= & \beta_{0}+\beta_{1} \text { InGDP }_{i}+\beta_{2} \text { INFR }_{i}+\beta_{3} \text { TERTENROL }+ \\
& \beta_{4} \text { URBANPOP }_{i}+\beta_{5} \text { ENGLISH }_{i}+\beta_{6} \text { GINI }_{i}+ \\
& \beta_{7} \text { FREEDOM }_{i}+\varepsilon_{i} .
\end{aligned}
$$

Our continuous independent variables include the natural log of GDP per capita measured at PPP (lnGDP); a telecommunications and technology infrastructure variable (INFR), which is calculated by taking the minimum of the telephone and PC penetration rate per 1,000 people for each country; ${ }^{4}$ the gross tertiary enrollment rate as a percentage of the population in the theoretical school-age group, that is, the five-year age group continuing on from the secondary school theoretical leaving age; as well as the percentage of urban population and the Gini Income Inequality Index. The model also includes two discrete independent variables: English and Freedom. The former is a dummy variable that takes on a value of 1 for countries in which English is an official language; the latter was obtained from Freedomhouse's Freedom Index, and ranges from 1 to 7, where 1 represents the highest degree of openness and freedom both in terms of civil liberties and political rights (thus the expected sign of the freedom 
coefficient is negative). Table 1 presents summary statistics and our main findings.

As is evident from Table 1, overall our model produced highly significant estimates. Moreover, the signs of the estimated coefficients all match the theoretical predictions, including the coefficient of the urban population variable, although the estimate is not significant at any reasonable level. ${ }^{5}$

The coefficient of GDP states that a percentage increase in GDP per capita, holding all other variables constant, will lead to an estimated increase of 0.49 Internet users per 1,000 inhabitants. Its elasticity at the centroid value indicates that a 1 percent increase in GDP per capita will lead to an approximate 0.11 percent increase in the Internet usage rate (IUR).

Our results also demonstrate that infrastructure, that is, access to PCs and telephone lines, plays an essential role in terms of Internet diffusion. Our model predicts that for every additional PC/phone line per 1,000 people, the IUR will increase by almost 0.5 . Thus, an increase in the number of computers available in a country will likely have a very large effect on Internet diffusion.

The coefficient of tertiary enrollment states that a 1 percent increase in enrollment will lead to an estimated 1.4 increase in the IUR. The coefficient is relatively small, yet significant nevertheless, indicating that increased enrollment does indeed have a positive effect on Internet penetration. This confirms our hypothesis that education has a positive effect on Internet diffusion.

Countries can expect to see Internet usage rates increase by 0.96 per percentage increase in the urban population. Note, however, that the coefficient of urban population is not significant; hence we should be wary of its interpretation.

Contrary to previous studies, our results support the claim that income inequality does indeed negatively influence Internet diffusion. According to our results, a 1 point increase on the Gini index, signifying greater inequality, will lead to an estimated 2.5 point decrease in the Internet usage rate.

Our findings also support the notion that freedom plays a relatively important role when it comes to penetration rates. For every unit decrease on the freedom scale (which corresponds to an increase in 


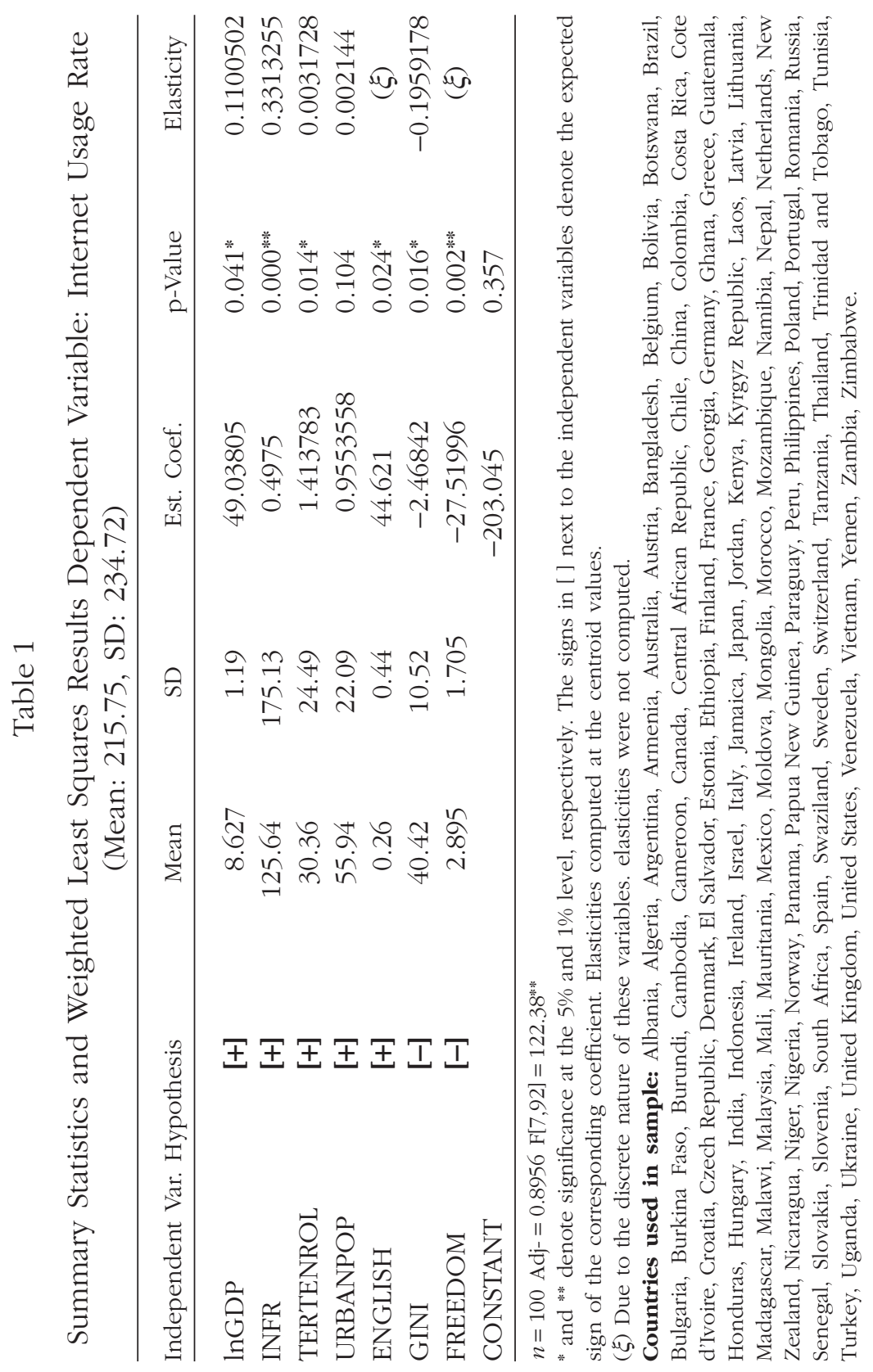


freedom and openness), the Internet usage rate is predicted to rise by 27.5 users per 1,000 inhabitants. Our model therefore predicts that countries with a high degree of openness will, all else being equal, have a substantial advantage over countries with restrictive regimes in terms of Internet diffusion.

Finally, our study also confirms that English is indeed a very significant determinant of Internet adoption. Countries that use English as an official language have an Internet usage rate that is on average 44.6 points higher than countries that do not.

Overall, our estimates support the findings of previous studies discussed in Sections II and III, but in some ways our results extend previous research. Our estimates also support the hypotheses that higher education and income equality do indeed have a significant positive impact on Internet diffusion, an effect that has been disputed in the past. Moreover, we have shown that the effect of PC and telecommunications infrastructure has a very strong and significant effect on Internet usage rates. Another important result of this research is that language plays a major role on the Internet. Expanding the Internet platform in (local) regional languages, in addition to English, would likely benefit the majority of the population in less developed countries.

\section{Conclusions and Policy Implications}

IN THIS STUDY, we set up an empirical model in an attempt to discover the main determinants of intercountry Internet penetration rates. Our results confirm past findings that economic strength, telecommunications and technology infrastructure, English proficiency, and a country's political and economic openness play a fundamentally important role in determining diffusion rates. In addition to these findings, we showed that tertiary enrollment and income equality also have a significant positive impact on Internet usage rates.

Given that the Internet is becoming increasingly important in today's societies, not just as a means of communication and source of information, but also in terms of cultural, ${ }^{6}$ economic, ${ }^{7}$ and political development, effort should be put into bridging the digital divide. Our 
results hint at various possible policies that may help accelerate the adoption of the Internet in developing countries, such as fighting income inequality and promoting higher education and the learning of the English language. ${ }^{8}$ Keniston (1997) makes a very strong case that the benefits of Internet usage can be experienced by the majority of the population in less developed countries only if we move away from an English-only Internet platform and embrace local languages. In a 2000 survey article, Madon provided an outstanding summary of documented research regarding the measurable impact of Internet usage in developing countries on economic productivity and infrastructure development, improving health, lowering costs of education, alleviating poverty, ${ }^{9}$ empowering marginalized groups, and promoting democracy and sustainable development.

One of the best approaches may be to focus on improving the existing infrastructure and increasing the availability of personal computers to the general population. In this spirit, the MIT Media Lab recently announced that it is working with governments in developing countries, especially in Africa, to provide \$100 laptops to students in these regions. The initiative, known as One Laptop per Child (OLPC), has received worldwide publicity and funding; the first prototype was unveiled in November 2005 by then U.N. Secretary-General Kofi Annan and Nicholas Negroponte, then the chairman of the MIT Media Lab. ${ }^{10}$ In addition to providing computers, the lab is also working hard to find ways of providing Internet connectivity to students at very low costs.

We look forward to future research geared toward assessing the impact of such projects and government policies aimed at increasing Internet usage in developing countries. Developed countries are not only able to use computers to optimize the production process but can also quickly access the Internet and employ this added knowledge to further optimize production. On the contrary, not only are developing countries limited by the lack of present technology, but growth is further stunted by the much slower access to information in the absence of computers. Hence, it is doubly crucial for poor countries to strain every nerve and sinew to stay afloat in the technological revolution by investing in it. Further research into the feasibility of utilizing technology in general, and the Internet in particular, for 
disseminating education and increasing democratic participation is a must. ${ }^{11}$ It will be interesting to see whether initiatives such as One Laptop per Child will affect the determinants of Internet diffusion, and whether they will ultimately help bridge the current digital divide.

\begin{abstract}
Notes
1. Internet World Stats, September 2006. See also Bauer, Berne, and Maitland (2002).

2. Details available at http://www.opera.com/voice/.

3. The Breusch-Pagan-Godfrey test confirmed that the errors of our nonweighted estimation had nonconstant variance, that is, were heteroskedastic. We corrected for heteroskedasticy by using the average cost of 20 hours of Internet as a percentage of GDP as a factor of proportionality.

4. The telephone and PC penetration rates exhibited a high degree of collinearity, evidenced by the very high correlation (0.92) of the two variables as well as their variance inflation factors (in excess of 10), which is why we chose to combine them into a single infrastructure variable. The idea behind taking the minimum of the two is that one can think of computers and telephones as both being essential for Internet access. Of course, recent advancements in Internet technology have diminished the reliance on telephone lines. However, for the time being this approximation makes sense, since the reach of such technologies is still fairly limited in most of the world. The model proposed here builds on some of the variables Murthy (2004) proposed in his econometric study.

5. Note that a lower value on the freedom index corresponds to a higher degree of freedom and openness. Thus the theoretical sign is negative.

6. We were unable to use firm-level data to see whether foreign versus domestic ownership matters in impacting the Internet diffusion rates across countries. For an excellent article in this critical area of research, please refer to Clarke (2004). This study was based on enterprise-level data of 21 lowand middle-income transition economies, in which the author demonstrated that foreign-owned firms experienced higher Internet adoption rates than domestic-owned firms and employee-owned firms.

7. One of the key economic benefits could be overall low inflation. Meijers (2006) showed that at least in the short run, increased Internet diffusion could lead to a "low inflation experience."

8. A study by Tan and Clark (2000) based on the data for the years 1994 and 2000 for the United States (where English is a dominant language) and China (where English is used only by the upper-end population) gives further support to the hypothesis that English proficiency is critical to a wider Internet diffusion across different demographic groups. In other words, their research
\end{abstract}


showed that the diffusion of the Internet into general population is faster in the United States (a developed country) than in China (a developing country).

9. For example, by providing critical weather and market information to farmers, relief workers, and researchers fighting crises caused by natural disasters. Another example is the success of the Village Internet Program of the Grameen Bank (Yunus 1998) in Bangladesh in promoting computer literacy among rural poor and by providing information about economic opportunities. Yunus, who is also the receipient of the 2006 Nobel Peace Prize for the work he has done regarding the Grameen Bank, stressed the importance of "information technology for the poor" in his acceptance speech delivered in Oslo, Norway on December 10, 2006.

10. Recent estimate for this type of computer is about $\$ 175$ as per the Economic Times dated May 7, 2007.

11. In a recent panel-data-based study covering a sample of 58 countries for years 1990 through 1999, Jamali, Wandschneider, and Wunnava (2007) demonstrated that increased usage of technology (proxied by 00 computers per 000 individuals) has a significant impact on economic growth (i.e., annual percentage growth in real GDP per capita).

\section{References}

Arnum, E., and S. Conti. (1998). "Internet Development Worldwide: The New Superhighway Follows the Old Wires, Rails, and Roads." Available at: http://www.isoc.org/inet98/proceedings/5c/5c_5.htm.

Bauer, J. M., M. Berne, and C. F. Maitland. (2002). "Internet Access in the European Union and in the United States." Telematics and Informatics 19: $117-137$.

Beilock, R., and D. V. Dimitrova. (2003). "An Exploratory Model of Intercountry Internet Diffusion." Telecommunications Policy 27: 237-252.

Buchner, B. J. (1988). "Social Control and the Diffusion of Modern Telecommunications Technologies: A Cross National Study." American Sociological Review 53(3): 446-453.

Chinn, M. D., and R. W. Fairlie. (2004). "The Determinants of the Global Digital Divide: A Cross-Country Analysis of Computer and Internet Penetration." Department of Economics, UCSC, Working Paper 562.

Clarke, G. R. G. (2004). "Effect of Enterprise Ownership and Foreign Competition on Internet Diffusion in the Transition Economies." Comparative Economic Studies 46: 341-370.

Crenshaw, E. M., and K. K. Robison. (2006). "Globalization and the Digital Divide: The Roles of Structural Conduciveness and Global Connection in Internet Diffusion." Social Science Quarterly 87(1): 190-207.

Guillen, M. F., and S. L. Suarez. (2001). "Developing the Internet: Entrepreneurship and Public Policy in Ireland, Singapore, Argentina, and Spain." Telecommunications Policy 25: 349-371. 
. (2004). "Explaining the Global Digital Divide: Economic, Political, and Sociological Drivers of Cross-National Internet Use." Wharton eBusiness Initiative Working Paper Series.

Hargittai, E. (1999). "Weaving the Western Web: Explaining Differences in Internet Connectivity Among OECD Countries." Telecommunications Policy 23: 701-718.

Jamali, K., K. Wandschneider, and P. V. Wunnava. (2007). "The Effect of Political Regimes and Technology on Economic Growth." Applied Economics 39(June): 1425-1432.

Keniston, K. (1997). "Software Localisation: Notes on Technology and Culture." Working Paper No. 26, Program in Science, Technology, and Society, MIT, Cambridge, MA.

Madon, S. (2000). "The Internet and Socioeconomic Development: Exploring the Interaction." Information Technology and People 13(2): 85-101.

Meijers, H. (2006). "Diffusion of the Internet and Low Inflation in the Information Economy." Information Economics and Policy 18: 1-23.

Murthy, V. N. R. (2004). "Internet Diffusion: An Econometric Analysis." AsianAfrican Journal of Economics and Econometrics 4(1): 45-54.

Tan, Z., and T. H. K. Clark. (2000). "Internet Diffusion in the USA and China." Info 2(6): 595-604.

Xiaoming, H., and C. S. Kay. (2004). "Factors Affecting Internet Development: An Asian Survey." First Monday 9(2).

Yunus, M. (1998). "Essays on Science and Society: Alleviating Poverty Through Technology." Science 282(5388): 409-410.

\section{Data Sources}

Human Development Reports: http://hdr.undp.org/

World Development Indicators: http://www.worldbank.org/

Internet World Stats: http://www.internetworldstats.com/

Freedomhouse's Freedom Index: http://www.freedomhouse.org/

Enthnologue: http://www.ethnologue.com/ 